\title{
Placental Polyp
}

National Cancer Institute

\section{Source}

National Cancer Institute. Placental Polyp. NCI Thesaurus. Code C3521.

A polyp in the uterine cavity that is formed by placenta remnants. 